\title{
Bridging Nanowires for Enhanced Gas Sensing Properties
}

\author{
Mohammad R Alenezi *(D) and Abdullah M. Almeshal \\ Electronics Engineering Technology Department, Collage of Technological Studies, PAAET, \\ Kuwait 70654, Kuwait; am.almeshal@paaet.edu.kw \\ * Correspondence: mr.alenezi@paaet.edu.kw; Tel.: +965-670-0046
}

Citation: Alenezi, M.R; Almeshal, A.M. Bridging Nanowires for Enhanced Gas Sensing Properties. Crystals 2021, 11, 743. https:// doi.org/10.3390/cryst11070743

Academic Editor: Vladislav V. Kharton

Received: 17 May 2021

Accepted: 23 June 2021

Published: 25 June 2021

Publisher's Note: MDPI stays neutral with regard to jurisdictional claims in published maps and institutional affiliations.

Copyright: (c) 2021 by the authors. Licensee MDPI, Basel, Switzerland. This article is an open access article distributed under the terms and conditions of the Creative Commons Attribution (CC BY) license (https:/ / creativecommons.org/licenses/by/ $4.0 /)$.

\begin{abstract}
It is crucial to develop new bottom-up fabrication methods with control over the physical properties of the active materials to produce high-performance devices. This article reports wellcontrolled, without seed layer and site-selective hydrothermal method to produce $\mathrm{ZnO}$ bridging nanowires sensors. By controlling the growth environment, the performance of the sensor became more efficient. The presented on-chip bridging nanowire sensor enhanced sensitivity toward acetone gas $(200 \mathrm{ppm})$ around 63 and fast response time $(420 \mathrm{~ms})$ and recovery time $(900 \mathrm{~ms})$. The enhancement in the speed of response and recovery is ascribed to the exceptional NW-NW junction barrier that governs the sensor's conductivity, and the excellent contact between $\mathrm{ZnO}$ nanowires and Au electrodes.
\end{abstract}

Keywords: nanowires; nanostructures; gas sensor; ZnO; hydrothermal

\section{Introduction}

The controlled synthesis of metal-oxide nanostructures (MONs)has advanced swiftly in recent years. Many researchers are still trying to understand how morphology, property, and application are related to achieving high functional devices. Among the most important devices are gas sensors, due to their crucial role in a wide range of important fields, including industrial process control, safety systems, disease diagnoses, and environmental monitoring [1-9].

As gas sensors, MONs are promising because they show high sensitivity and fast response to low concentrations of gases. As a consequence of their very small size, MONs resistance can easily be influenced by changes at their surfaces because the effect of surface interactions can extend to a distance from the surface that is comparable to the dimensions of the MONs [10-18]. The sensing mechanism of MONs depends on activating the surface atmospheric oxygen at relatively high operating temperatures. Accordingly, the reactions on the surface will free more electrons and transfer them from the surface to the bulk of MONs, and this process is responsible for changing their resistance [4].

One of the most studied MONs ever is zinc oxide ( $\mathrm{ZnO})$. Various studies about $\mathrm{ZnO}$ nanostructures synthesis, characterization, and many applications can be found in the literature [1-9]. ZnO has a broad range of morphologies, including nanowires (NWs), nanodisks (NDs), nanoleaves, nanorings, nanoflowers, nanobrushes, and many other hierarchical nanostructures. Moreover, $\mathrm{ZnO}$ has been studied for its potential in many key applications like electronics, optics, sensors, actuators, and piezoelectronics [1-9]. Gas sensing significant field, due to the large number of gases that can be harmful to organic life [3]. Gas sensors can be used to detect combustible, flammable, and toxic gases. Gas sensors are used in numerous applications are integrated within various industrial plants, pharmaceutical manufacturing, waste-water treatment facilities, vehicles, indoor air quality testing, and homes.

Gas sensors fabricated using $\mathrm{ZnO}$ thin film are usually not sensitive enough and take a long time to respond. Alternatively, $\mathrm{ZnO}$ nanostructures are more sensitive and can detect a much lower concentration of gases in a relatively shorter time because of their higher surface-to-volume ratio and smaller size [10-18]. 
So far, nanostructured gas sensors are fabricated by two primary techniques. One technique requires a precise pick and place procedure of a single nanostructure and then depositing contacts to it by electron beam lithography. This technique is obviously costly and not applicable for large-scale production [3]. The other technique requires multiple procedures, such as synthesis, sonication, and transferring of nanostructures between substrates and prepatterning substrates with electrodes. It is evident that these techniques are complicated and limit the practical applications of nanostructured gas sensors [1-4].

Many synthesis methods were used to grow $\mathrm{ZnO}$ nanostructures, including physical vapor phase deposition, metal-organic chemical vapor deposition, and hydrothermal synthesis [1]. Some of these methods require high synthesis temperatures, and this can limit its uses and applications significantly. The hydrothermal synthesis of $\mathrm{ZnO}$ nanostructures is more preferred because of its low cost, the possible large-scale production, and a more comprehensive range of substrates that can be used in it. However, in many of the previously reported hydrothermal syntheses of $\mathrm{ZnO}$ nanostructures, a predeposited seed layer at a relatively high temperature is required. However, this takes us back to the disadvantages of the high temperature synthesis methods. Moreover, it is not suitable for many applications, since this extra layer has a negative effect on the contact between the nanostructure and substrate.

When using HMTA in the hydrothermal synthesis of ZnO NWs, HMTA hydrolyzes into formaldehyde and ammonia during the NWs growth process [19], acting as a $\mathrm{pH}$ buffer by slow decomposition to provide ammonia gradually, which can support $\mathrm{OH}^{-}$by forming ammonium hydroxide. $\mathrm{OH}^{-}$and $\mathrm{Zn}^{2+}$ can complex to form several monomeric hydroxyl species [20]. The formation of solid $\mathrm{ZnO}$ nuclei can then be achieved when the hydroxyl species dehydrate. The growth of $\mathrm{ZnO}$ crystals proceeds by condensing the surface hydroxyl groups with the zinc-hydroxyl complexes [2,3].

In our growth solutions, the amount of zinc nitrate is double that of HMTA. In this case, the growth environment is supersaturated with regard to $\mathrm{ZnO}$ or $\mathrm{Zn}(\mathrm{OH})_{2}$. This usually leads to most of the nutrient depletion by forming $\mathrm{ZnO}$ solid in the bulk solution through homogeneous nucleation. Therefore, ammonium hydroxide is introduced to the growth process to overpower the homogeneous nucleation. Ammonium hydroxide is responsible for the coordination of ammonia to $\mathrm{Zn}^{2+}$, decreasing the number of free $\mathrm{Zn}^{2+}$ [21]. These complexes buffer the $\mathrm{Zn}^{2+}$ ions and supply the growth environment with them gradually to avoid supersaturation. Conversely, preparing the $\mathrm{ZnO}$ seed layer on the substrate before starting the growth process allows $\mathrm{ZnO}$ NWs to grow without the initial nucleation phase. However, high ammonium hydroxide concentration in the growth environment can slow the growth severely because it causes an extremely low supersaturation degree. Hence, it is necessary to include other growth-supporting factors to improve the aspect ratio of the grown NWs. Polyethyleneimine (PEI) is known to make $\mathrm{ZnO}$ NWs to grow longer. It prevents radial growth and only allows the NWs to grow in the $c$ direction by attaching to the nonpolar facets of the forming crystal [2,21]. PEI prevents any homogeneous nucleation and improves the aspect ratio of the $\mathrm{ZnO}$ NWs grown on substrates with large enough preexisting seeds $(5-20 \mathrm{~nm})$.

In this report, we present the fabrication method of nanostructured $\mathrm{ZnO}$ gas sensors directly on the substrate. The hydrothermal method is seedless and site-selective. The sensor structure is made more efficient to improve the sensitivity, and speed of response and recovery. Employing this fabrication method, gas sensors are fabricated on flexible and transparent substrates, and the fabricated bridging NWs (BNWs) are compared with two other sensors having different device structures, the NW array (NWA) and single NWs (SNWs) devices.

\section{Materials and Methods}

Gas sensors are fabricated on $\mathrm{Si} / \mathrm{SiO}_{2}$ and Polyethylene terephthalate (PET) substrates with prepatterned Au electrodes. A thin layer of $20 \mathrm{~nm} \mathrm{Cr}$ was deposited first as the adhesion layer before the deposition of a $50 \mathrm{~nm}$ thick Au layer. The precursor chemicals 
involved in the synthesis are zinc nitrate hexahydrate $\left(\mathrm{Zn}\left(\mathrm{NO}_{3}\right)_{2} \cdot 6 \mathrm{H}_{2} \mathrm{O}, 98 \%\right.$, reagent grade, Sigma Aldrich, St. Louis, MO, United States), HMTA, ammonium hydroxide $\left(\mathrm{NH}_{3} \cdot \mathrm{H}_{2} \mathrm{O}\right.$, 28-30 wt\%, reagent grade, Sigma Aldrich), and polyethylenimine (PEI) (end-capped, molecular weight $800 \mathrm{~g} / \mathrm{mol}$ LS, Aldrich).

In the fabrication of BNWs sensors, substrates with prepatterned Au electrodes were put face-down in a vial containing $\mathrm{Zn}\left(\mathrm{NO}_{3}\right)_{2} \cdot 6 \mathrm{H}_{2} \mathrm{O}(25 \mathrm{mM})$, HMTA $(12.5 \mathrm{mM})$, and $\mathrm{NH}_{3} \cdot \mathrm{H}_{2} \mathrm{O}(0.35 \mathrm{M})$ as an initial growth stage where the vial was heated in an oven at $85^{\circ} \mathrm{C}$ for $45 \mathrm{~min}$. The secondary growth stage was started by replacing the growth solution in the vial with a mixture solution of $\mathrm{Zn}\left(\mathrm{NO}_{3}\right)_{2} \cdot 6 \mathrm{H}_{2} \mathrm{O}(10 \mathrm{mM})$, HMTA $(5 \mathrm{mM}), \mathrm{NH}_{3} \cdot \mathrm{H}_{2} \mathrm{O}$ $(0.35 \mathrm{M})$, and PEI $(5 \mathrm{mM})$. The process was conducted within $3 \mathrm{~h}$ at the same temperature. After the growth is terminated, the substrate was washed with DI water and annealed at $150{ }^{\circ} \mathrm{C}$ for $10 \mathrm{~min}$.

$\mathrm{ZnO}$ NWA and SNWs gas sensors were fabricated for sensor performance comparison. For $\mathrm{ZnO}$ NWA devices, the prepatterned substrate was spin-coated with $5 \mathrm{mM}$ zinc acetate dehydrate $\mathrm{Zn}\left(\mathrm{CH}_{3} \mathrm{COO}\right)_{2} \cdot 2 \mathrm{H}_{2} \mathrm{O}$ solution in acetone at $1000 \mathrm{rpm}$ for $30 \mathrm{~s}$. The spin-cast layer on the substrate was cured on a hot plate at $150{ }^{\circ} \mathrm{C}$ for $5 \mathrm{~min}$ to stabilize the film structure. The spin-coating and curing processes were repeated five times to obtain a uniform film, which served as the seeding layer. Afterward, the film was thermally annealed at $350{ }^{\circ} \mathrm{C}$ for $30 \mathrm{~min}$, and then allowed to cool down. The thermal decomposition (of the zinc acetate) created $\mathrm{ZnO}$ nanocrystals on the substrate that act as a seed layer for subsequent $\mathrm{ZnO}$ array growth. The precursor solution for the hydrothermal reaction consists of $\mathrm{Zn}\left(\mathrm{NO}_{3}\right)_{2} \cdot 6 \mathrm{H}_{2} \mathrm{O}(25 \mathrm{mM})$, HMTA $(12.5 \mathrm{mM})$, PEI, $(5 \mathrm{mM})$, and $\mathrm{NH}_{3} \cdot \mathrm{H}_{2} \mathrm{O}(0.35 \mathrm{M})$. The seeded substrate was then placed in a vial that contains $15 \mathrm{~mL}$ of the growth solution. The vial was covered and then placed in an oven and heated at $85^{\circ} \mathrm{C}$ for $7 \mathrm{~h}$. after the growth is terminated, the substrate was then rinsed with DI water and dried in air at $150{ }^{\circ} \mathrm{C}$ for $30 \mathrm{~min}$.

SNWs devices were fabricated by drop-casting a solution containing $\mathrm{ZnO} N W$ s on substrates with Au prepatterned electrodes. The substrate was annealed at $200{ }^{\circ} \mathrm{C}$ for $2 \mathrm{~h}$ for better contact between the NWs and the electrodes.

The morphology and crystal structure of as-prepared products were observed using Philips XL-20 scanning electron microscope at $10 \mathrm{kV}$. The electrical characteristics and gas sensing properties of the fabricated devices were recorded using a probe station in a homemade chamber attached to a Keithley 4200 semiconductor analyzer. The sensor response, $S$, is defined as $S=\left(I_{g}-I_{a}\right) / I_{a}$, where $I_{g}$ is the current sensor value in the tested gas environment and $I_{a}$ is the current value in air. The measurements were performed under a fixed bias of $2 \mathrm{~V}$. The response time, $t_{r}$, is defined as the time required for the current to reach $90 \%$ of the equilibrium value after injecting the gas, and the recovery time, $t_{d}$, is defined as the time necessary for the sensor to return to $10 \%$ above the original current value in the air after releasing the gas from the test chamber.

\section{Results and Discussion}

Three $\mathrm{ZnO}$ gas sensors with different device structures, NWA, SNW, and BNW, were fabricated using hydrothermal synthesis, and their gas sensing properties were tested. Due to the critical impact of the operating temperature on the $\mathrm{ZnO}$ gas sensors, all fabricated sensors were tested at different temperatures to find the optimum condition for acetone gas sensing. Figure 1 shows the responses of all tested sensors to $200 \mathrm{ppm}$ acetone as a function of the operating temperature. All sensors behave similarly in general. For all sensors, the sensitivity increases as the temperature increases, up to a certain point, and after that, the sensitivity starts to decrease with further increases in the temperature. $\mathrm{ZnO} N W A, \mathrm{SNW}$, and BNW sensors were most sensitive at 375,325 , and $275^{\circ} \mathrm{C}$, respectively. $\mathrm{ZnO}$ needs enough thermal energy to be activated and be able to sense. When reducing gases, such as acetone, are presented, the adsorbed oxygen on the $\mathrm{ZnO}$ surface takes part in the oxidation of acetone. The oxygen ions on the surface of $\mathrm{ZnO}$ react with the acetone molecules and give up electrons to the conduction band. At low operating temperature, the sensitivity 
is low, due to insufficient chemical activation [22]. Ionized oxygen is chemisorbed onto the surface of $\mathrm{ZnO}$ in its molecular form, $\mathrm{O}^{2-}$ which is less reactive [23]. At higher temperatures around the optimum, oxygen ion molecules are dissociated into oxygen ions with singly, $\mathrm{O}^{-}$, or doubly negative electric charges, $\mathrm{O}^{2-}$, by attracting an electron from the conduction band of the $\mathrm{ZnO}$. This substantial resistance increase, due to the depletion of $\mathrm{ZnO}$ by the adsorbed oxygen enhances the sensitivity of $\mathrm{ZnO}$ gas sensors [24,25]. These two processes, thermal excitation of electrons and chemisorption of oxygen species, carry on until the whole $\mathrm{ZnO}$ surface is covered with oxygen species, and this is where the optimum operating temperature is reached. After this stage, no more oxygen species can be absorbed, and electrons thermal excitation overcomes, leading to lower sensitivity, as seen in Figure 1. In fact, working at very high temperatures improves the activation significantly and forces the adsorbed gas molecules on the sensor surface to depart before getting the chance to exchange charges with the surface $[4,7]$.

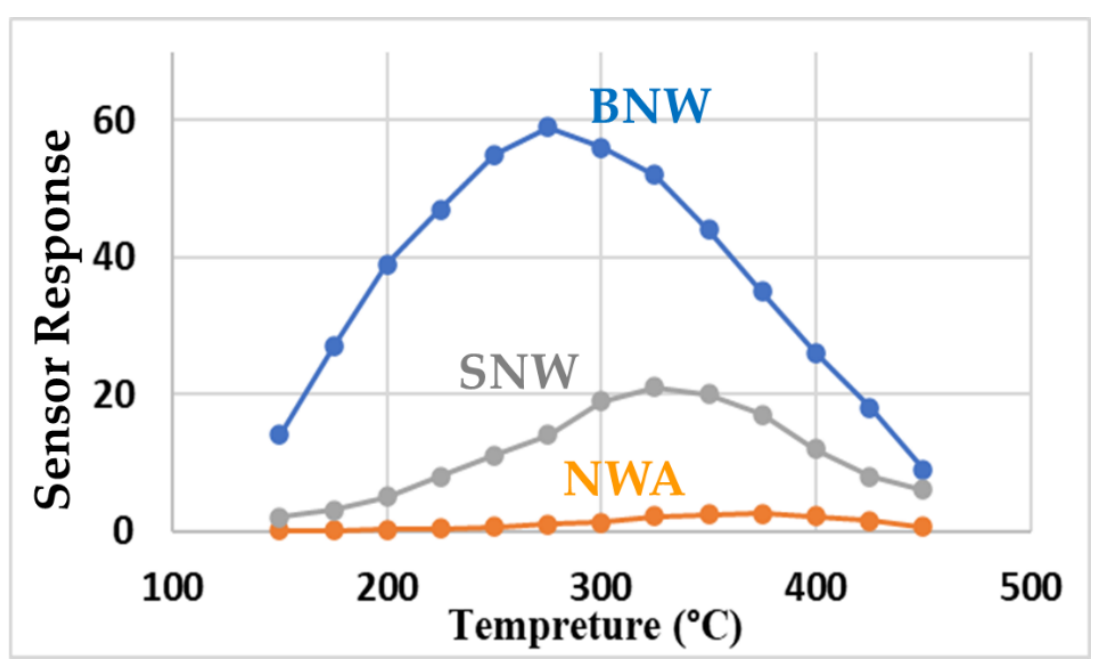

Figure 1. Sensor response versus operating temperature curves of the three sensors at $200 \mathrm{ppm}$ of acetone.

Figure 2a,b depicts two SEM images of the NWA devices. One can see the well-aligned $\mathrm{ZnO}$ NWs and how uniform they are. A schematic of the NWA device is presented in Figure 2c. The sensitivity characteristics of the NWA sensor are shown in Figure 2d. The response of the sensor to $200 \mathrm{ppm}$ of acetone gas at $375^{\circ} \mathrm{C}$ is about 2.7. The sensor took $42 \mathrm{~s}$ to respond and $56 \mathrm{~s}$ to recover to its original state. The two electrodes in this device are connected by the seed layer under the NW array that consists of a polycrystalline thin film with nanoparticles ranging between $(300-400 \mathrm{~nm})$. The device response is stable, but it takes very long to reach its baseline again. Moreover, it showed poor sensitivity and extended the response and recovery times. Furthermore, in this device's fabrication procedure, the seed-layer needed to be annealed at a relatively high temperature $\left(400{ }^{\circ} \mathrm{C}\right)$, which does not allow the use of flexible substrates.

ZnO SNWs gas sensor was also tested at its optimum operating temperature under an acetone gas concentration of $200 \mathrm{ppm}$. SEM images, schematic, and gas sensing characteristics of the ZnO SNWs sensor are shown in Figure 3. The sensitivity of this device to acetone has been significantly improved relative to the previous $\mathrm{ZnO}$ NWA sensor. The response to $200 \mathrm{ppm}$ of acetone is about 26 and the response time and recovery-time are 6 and $8 \mathrm{~s}$, respectively. The enhancement in this device performance over the NWA sensor was anticipated because of the reduced size of the active sensing part in the SNWs sensor and increased surface to volume ratio [26,27]. 

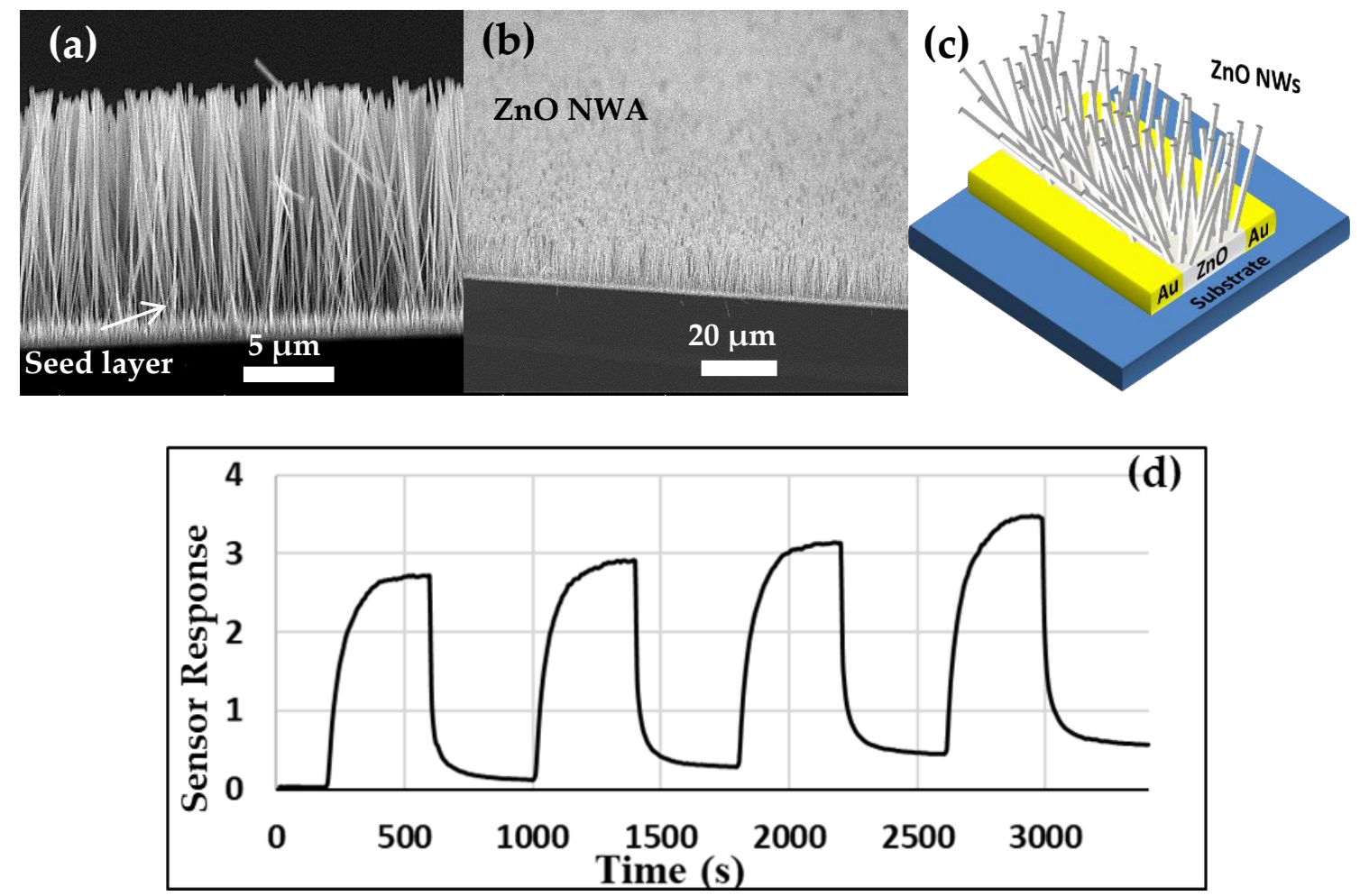

Figure 2. (a,b) SEM images, (c) a schematic diagram, and (d) the gas sensing characteristics of the ZnO NWA sensor to 200 ppm of acetone.
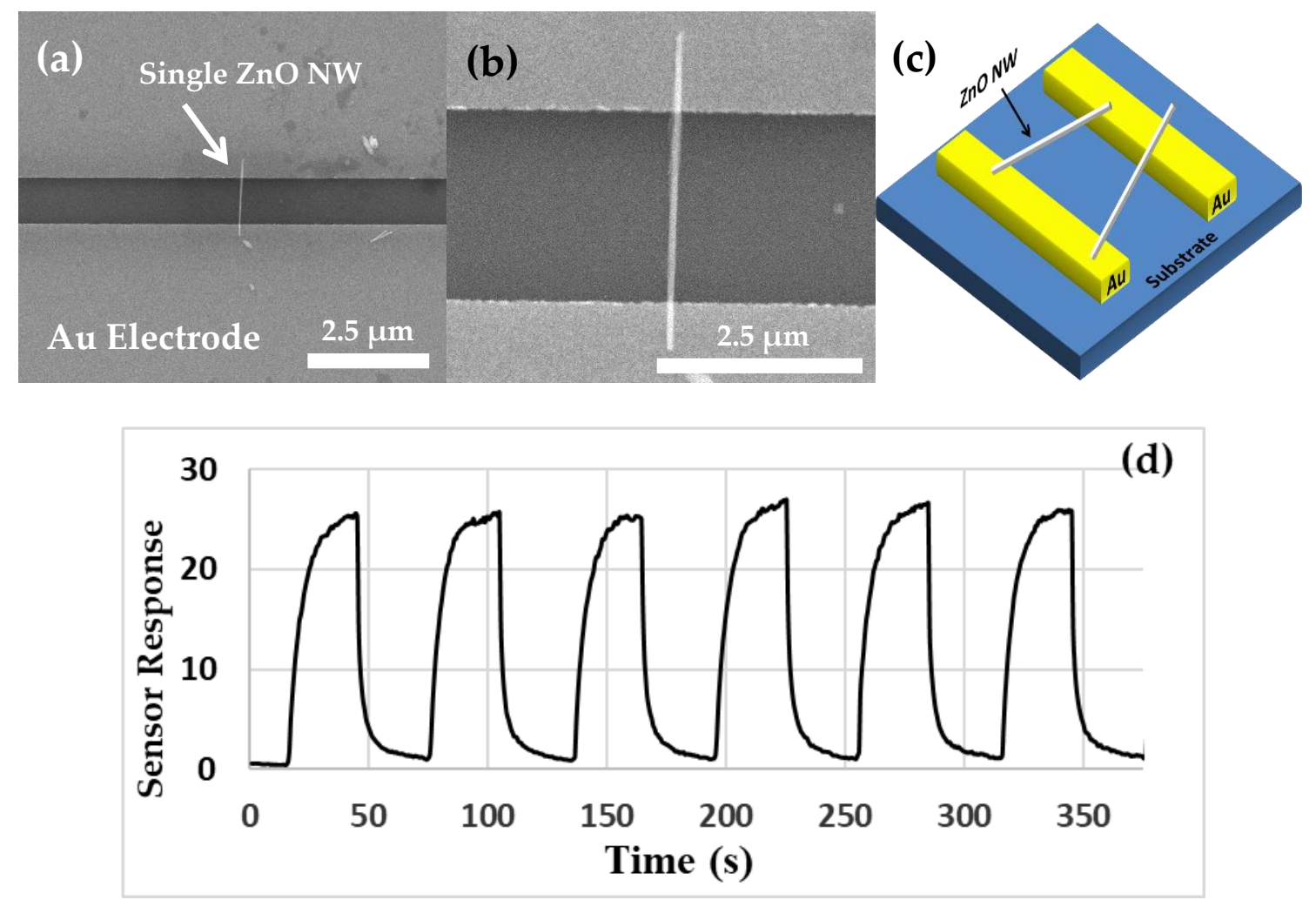

Figure 3. (a,b) SEM images (2.5 $\mu \mathrm{m}$ space between the Au electrodes), (c) a schematic diagram, and (d) the response characteristics of the $\mathrm{ZnO}$ SNWs detector to $200 \mathrm{ppm}$ acetone gas. 
Our goal in this study is to develop a more efficient device structure that can improve sensor performance and be fabricated using flexible and transparent substrates. To reach this goal we should achieve the following: (1) Create better contact between the NWs and the electrodes by growing the NWs on the electrodes without any separating seed layer, (2) control the charge transport by including (NW-NW junction) where the effect of gas present at the on the potential barrier is greatest, and (3) reduce the size of the active sensing material.

To achieve these tasks, we had to modify our hydrothermal growth method. The growth solution and the substrate were altered to produce $\mathrm{ZnO}$ NWs directly and selectively on the electrodes, as shown in the SEM images in Figure 4. The ZnO NWs are grown on the Au electrodes that were prepatterned on the $\mathrm{Si} / \mathrm{SiO}_{2}$ substrate selectively without the need for a seed layer. The growth solution consisted of $\mathrm{Zn}\left(\mathrm{NO}_{3}\right)_{2} \cdot 6 \mathrm{H}_{2} \mathrm{O}(25 \mathrm{mM})$, HMTA $(12.5 \mathrm{mM})$, and $\mathrm{NH}_{3} \cdot \mathrm{H}_{2} \mathrm{O}(0.35 \mathrm{M})$. Due to the strong prohibition of homogeneous nucleation in the solution and strong heterogeneous nucleation on Au surfaces only in this growth environment, $\mathrm{ZnO}$ NWs were only grown preferentially on Au prepatterns, as shown in Figure 4.

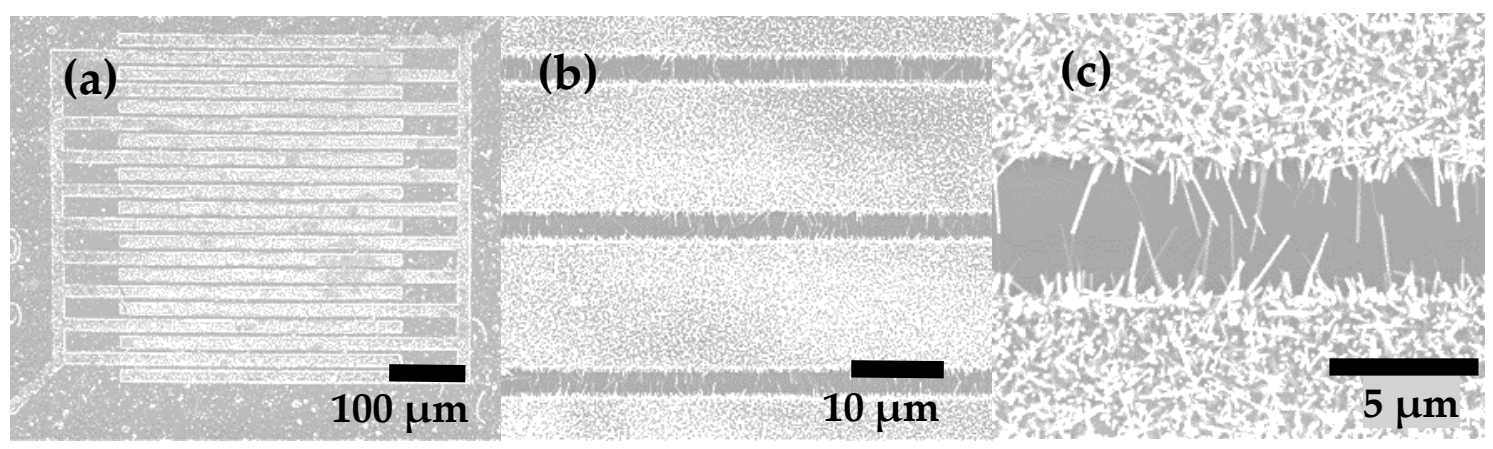

Figure 4. (a-c) SEM images of $\mathrm{ZnO} N W s$ on $\mathrm{Si} / \mathrm{SiO}_{2}$ substrates with prepatterned Au electrodes at different magnifications. (The spacing between the electrodes in all images is $5 \mu \mathrm{m}$ ).

From our experiments and the literature [21], we know that increasing the concentration of ammonium hydroxide in the growth environment can improve the heterogeneous nucleation of $\mathrm{ZnO}$ on Au surfaces, and consequently, the NWs' density the cost of slowing the growth process. Once again, we decided to use PEI to accelerate and enhance the growth process of $\mathrm{ZnO}$ NWs. However, we discovered that adding PEI from the start, before the nucleation occurs, interrupts the whole growth process. A similar observation was also reported by another study in the literature [28]. Thus, we decided to introduce PEI gradually after the nucleation occurs after $30 \mathrm{~min}$ from the beginning of the growth process.

The modified hydrothermal synthesis method was used to fabricate $\mathrm{ZnO}$ BNWs sensors on flexible and transparent substrates. SEM images at different magnifications and schematic of the BNWs sensor are presented in Figure 5a-d, respectively. In these SEM images, one can see the bridging NWs and the contact nano junctions between them. The BNWs sensor performance characteristics are shown in the plot in Figure 5e. The sensor response to $200 \mathrm{ppm}$ acetone is around 63 . The response-time and the recovery-time of the BNWs device are 0.42 and $0.90 \mathrm{~s}$, respectively. The BNWs sensor is faster than the NWA 105 times and 15 times faster than the SNWs sensor. The enhancement in the BNWs sensor performance stems from several factors, including the more efficient device structure with junctions between the NWs and stronger contact between the NWs and the electrodes. 

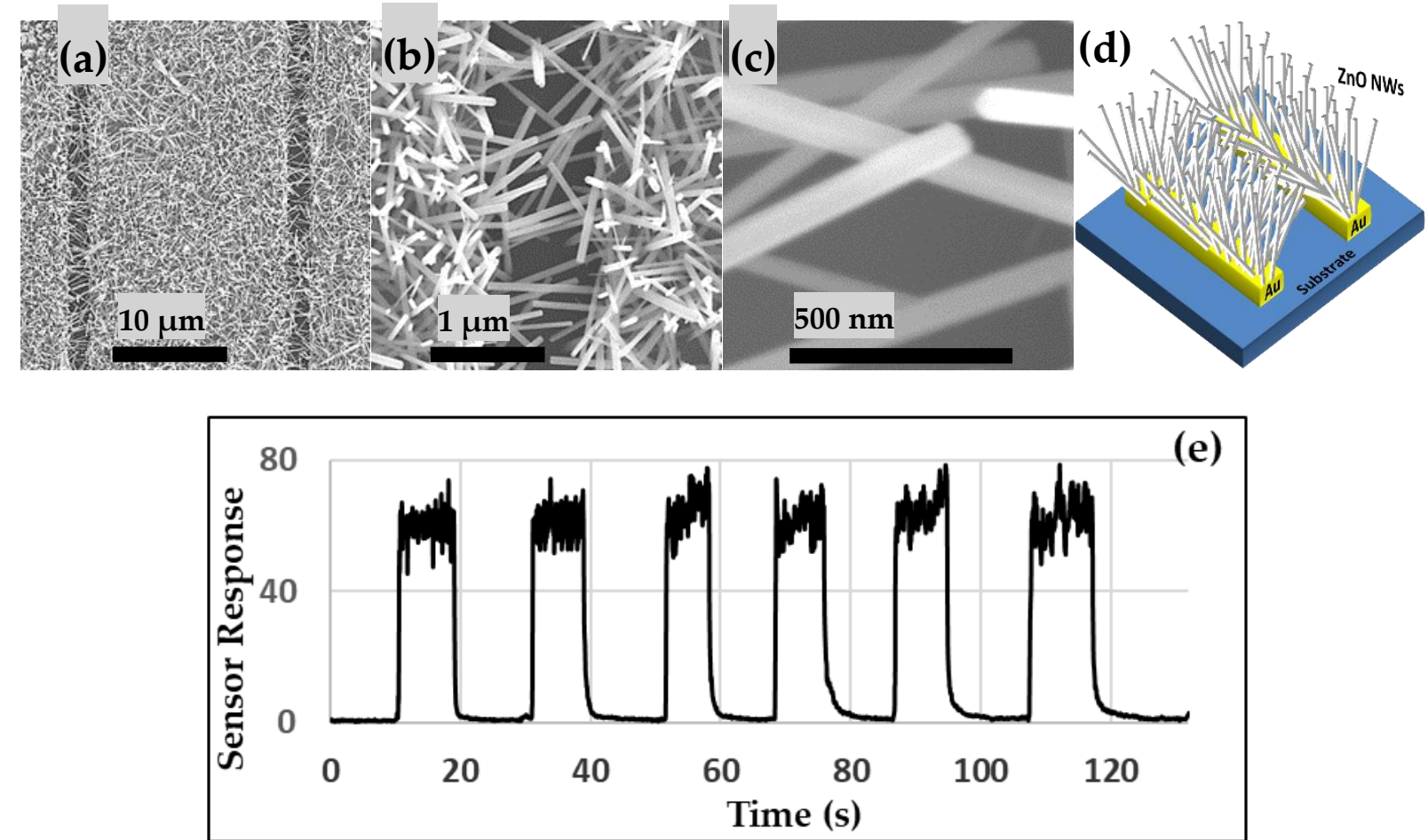

Figure 5. (a-c) SEM images at different magnifications, (d) a schematic diagram, and (e) response characteristics of the $\mathrm{ZnO}$ BNWs sensor.

Figure 6 shows the sensitivity of the different fabricated gas sensors as a function of gas concentration. Each sensor was tested at its optimum working temperature. The order of sensitivities was as follows: $\mathrm{BNW}>\mathrm{SNW}>\mathrm{NWA}$ along with the whole concentration range. The $\mathrm{ZnO}$ BNW sensor was the most sensitive, while the NWA sensor displayed the lowest. When the concentration of acetone exceeded $500 \mathrm{ppm}$, all sensors started to show a sign of saturation at different levels. Table 1 compares the performance of the different fabricated gas sensors in this work to $\mathrm{ZnO}$ gas sensors of different morphologies from the literature toward acetone gas.

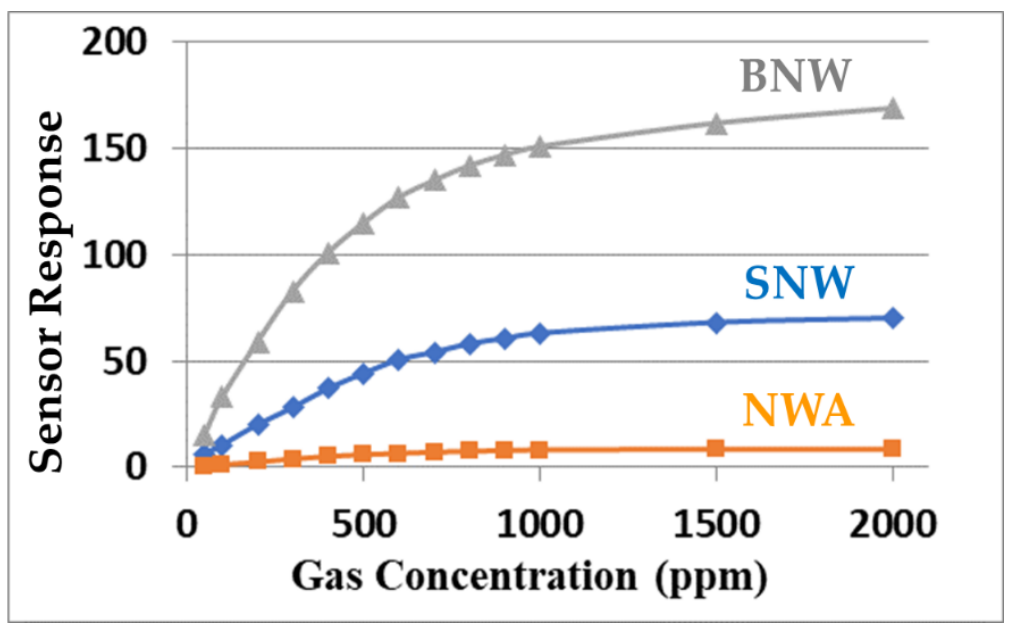

Figure 6. Sensor response as a function of the acetone concentration of the three sensors.

The generation and transportation of charges inside the SNWs sensor and the BNWs sensor are schematically represented in Figure 7. The scheme also compares the transport mechanisms in the SNWs and BNWs sensors. The sensing mechanism of $\mathrm{ZnO}$ nanostruc- 
tures depends significantly on the change in the nanostructure resistance, which is governed mainly by gas molecules adsorption and desorption processes on the surface [10-18,22-26]. This mechanism can be explained by the depletion region modulation model, as shown in Figure 7 [29,30]. In ambient air, the $\mathrm{ZnO}$ nanostructure adsorbs oxygen species on the surface, attracting free electrons from the conduction band and forming chemisorbed oxygen species, as shown in the first row of Figure 7. There are different oxygen species, such as molecular $\left(\mathrm{O}_{2}^{-}\right)$and atomic $\left(\mathrm{O}^{-}, \mathrm{O}^{2-}\right)$ ions on the surface, depending on the operating temperature. For metal oxides in general, a relatively high temperature $\left(150-500{ }^{\circ} \mathrm{C}\right)$ is required to reach a reasonable sensing performance. The process of attracting and seizing free electrons from the conduction band extends the width of the depletion region near the surface, and consequently, increases the resistance of the nanostructure, as represented in the second row of Figure 7. When acetone gas molecules are introduced in the gas chamber, as shown in the third row of Figure 7, they go through an oxidation process with the chemisorbed oxygen species on the surface. This oxidation process results in the release of all previously seized electrons from the conduction band as summarized in the following Equation (1) [31]:

$$
\mathrm{CH}_{3} \mathrm{COCH}_{3}+8 \mathrm{O}^{-} \text {(ads) } \Leftrightarrow 3 \mathrm{CO}_{2}+3 \mathrm{H}_{2} \mathrm{O}+8 \mathrm{e}^{-}
$$
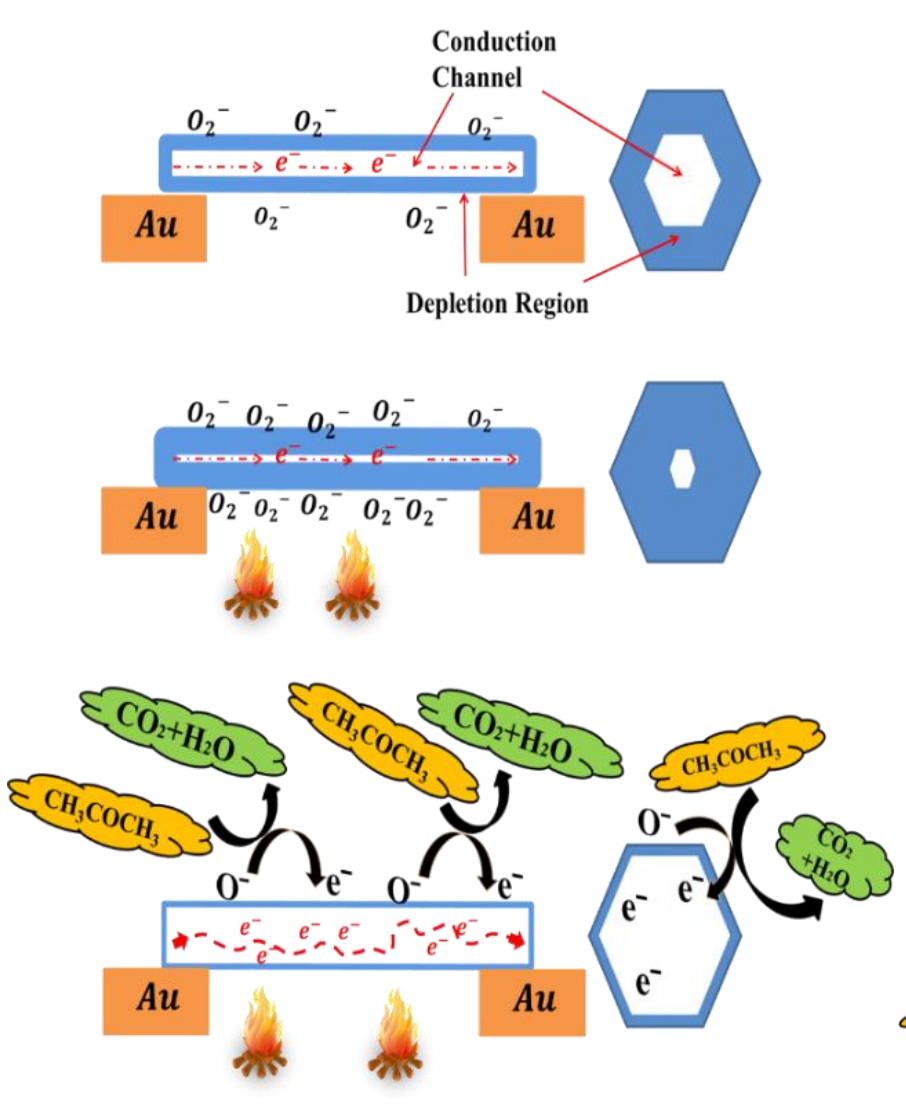

Figure 7. A schematic diagram, representing the carrier generation and transportation in the SNWs vs. BNWs sensors.

This reaction reduces the width of the depletion region near the surface of the $\mathrm{ZnO}$ nanostructure and consequently decreases its resistance. On the $\mathrm{ZnO}$ nanostructure surface, oxygen vacancies behave like donors, while adsorbed oxygen ions act as surface acceptors. The more oxygen vacancies available on the surface of the $\mathrm{ZnO}$ nanostructure, the better its interaction with gas molecules and subsequently its gas sensing properties [29]. 
The conduction channel in the BNWs sensor includes NW-NW junctions, and charges need to cross them for the current to flow. The barrier consists of the surface depletion layers from both NWs. The expression for the $\mathrm{ZnO}$ NW conductance is as follow:

$$
G=\mathrm{n}_{0} e \mu \pi\left(D-2 t_{\mathrm{c}}\right) / 4 l
$$

where $\mathrm{n}_{0}$ is the free charge carrier density, $\mu$ is the charge carriers' mobility, $D$ is the NW diameter, $t_{\mathrm{c}}$ is the thickness of the surface charge region, $l$ is the length between the two electrodes. The thickness of the depletion region $t_{\mathrm{c}}$ is expressed as:

$$
t_{\mathrm{c}}=\mathrm{L}_{\mathrm{D}}\left(e \mathrm{~V}_{\mathrm{S}} / k T\right)^{1 / 2}
$$

where $L_{D}$ is the Debye length and $V_{S}$ represents the adsorbate induced band bending. The Debye length is expressed as:

$$
\mathrm{L}_{\mathrm{D}}=\left(\varepsilon \varepsilon_{0} \mathrm{kT} / e^{2} \mathrm{n}_{0}\right)^{1 / 2}
$$

where $\varepsilon$ is the relative dielectric permittivity [32]. The charges to flow between the NWs must first cross the depletion regions that act as barriers. Thus, for the NWs with diameters greater than the Debye length, the major modulator of charge flow in the BNWs sensors is the junction between the connected NWs.

\begin{tabular}{|c|c|c|c|c|c|}
\hline Morphology & $\begin{array}{c}\text { Operating } \\
\text { Temperature }\left(\mathrm{C}^{0}\right)\end{array}$ & $\begin{array}{l}\text { Concentration } \\
\text { (PPM) }\end{array}$ & Response & $\begin{array}{c}\text { Response/Recovery } \\
\text { Time (s) }\end{array}$ & Ref \\
\hline Hierarchical $\mathrm{ZnO}$ nanowires & 425 & 100 & 44 & $2 / 4$ & [3] \\
\hline $\mathrm{ZnO} /$ graphene composites & 280 & 10 & 1.4 & $1 / 2$ & [13] \\
\hline Sn-doped $\mathrm{ZnO}$ nanosheets & 320 & 100 & 3.9 & $10 / 4$ & [15] \\
\hline $\mathrm{ZnO}$ nanosheets & 360 & 50 & 31 & $2 / 15$ & [16] \\
\hline $\mathrm{ZnO}$ flakes & 485 & 100 & 22.2 & $-/-$ & [17] \\
\hline $\mathrm{ZnO}-\mathrm{CuO}$ nanoflakes & 300 & 10 & 12.6 & $22 / 26$ & [18] \\
\hline $\mathrm{Pd}-\mathrm{ZnO}$ nanosheets & 340 & 100 & 70 & $9 / 6$ & [33] \\
\hline $\mathrm{ZnO}$ microspheres & 330 & 400 & 30 & & [34] \\
\hline Flower-like $\mathrm{ZnO}$ & 280 & 1000 & 88.3 & & [35] \\
\hline ZnO Nanocomb & 200 & 1 & 5.4 & $0.8 / 0.4$ & [36] \\
\hline ZnO nanowire array NWA & 375 & 200 & 2.7 & $42 / 56$ & \multirow{3}{*}{$\begin{array}{l}\text { This work } \\
\text { This work }\end{array}$} \\
\hline ZnO Single nanowire SNW & 325 & 200 & 26 & $6 / 8$ & \\
\hline ZnO Bridging nanowires BNW & 275 & 200 & 60 & $0.42 / 0.9$ & \\
\hline
\end{tabular}

Table 1. A comparison between the fabricated $\mathrm{ZnO}$ nanostructure acetone gas sensors in this work and some of the reported sensors in the literature.

The improvement in response-time and recovery-time of the BNWs sensors can be ascribed mainly to the domination of the NW-NW junction barrier over the charge transport. Oxygen diffusion and adsorption again to deplete the NW channel takes a very long time. Therefore, if the sensor conductance is controlled by an NW conductance only, then it will take too long for the charge to recover. On the other hand, the conductance of the BNWs sensor is controlled more efficiently by the NW-NW junction barriers, where the flow of charges across the junction barrier is exponentially related to the barrier height. That is why the flow of charges is so sensitive to changes in the barrier. As soon as the gas gets out of the chamber, the electron-hole pairs recombine immediately, and the number of free charges in the NW will reduce accordingly, causing a swift increase in the effective barrier. 
Therefore, the junction barrier can lower the flowing current efficiently. The modulation of the barrier height is much faster than the oxygen diffusion process [2].

\section{Conclusions}

In conclusion, we reported a controlled seedless and site-selective hydrothermal synthesis method to produce ZnO NWs. Gas sensors with different device structures were fabricated on-chip and tested. We demonstrated that by controlling the grown NWs, by tuning the growth parameters, the device performance can improve significantly. Using this method, high performance gas sensors were fabricated on flexible and transparent substrates and were compared with two other sensors having different device structures, the NWA and SNWs devices. The BNWs gas sensor demonstrated improved sensitivity toward acetone, excellent detectability, and short response-time $(420 \mathrm{~ms})$ and recovery-time $900 \mathrm{~ms}$ ). The enhancement in response and recovery times of the BNWs device was ascribed to the NW-NW junction barrier dominated resistance, and the direct contact between the $\mathrm{ZnO}$ and the Au electrode was unavailable for the other devices.

Author Contributions: Conceptualization, M.R.A. and A.M.A.; methodology, M.R.A.; validation, A.M.A.; investigation, M.R.A. and A.M.A.; writing—original draft preparation, M.R.A.; writingreview and editing, M.R.A. and A.M.A.; supervision, M.R.A.; All authors have read and agreed to the published version of the manuscript.

Funding: This research received no external funding.

Acknowledgments: M.R.A. thanks by the Public Authority of Applied Education and Training (PAAET) and the government of the state of Kuwait.

Conflicts of Interest: The authors declare no conflict of interest.

\section{References}

1. Wang, Z.; Gong, J.; Su, Y.; Jiang, Y.; Yang, S. Six-Fold-Symmetrical Hierarchical ZnO Nanostructure Arrays: Synthesis, Characterization, and Field Emission Properties. Cryst. Growth Des. 2010, 10, 2455-2459. [CrossRef]

2. Alenezi, M.R.; Henley, S.J.; Silva, S.R.P. On-chip Fabrication of High Performance Nanostructured ZnO UV Detectors. Sci. Rep. 2015, 5, 8516. [CrossRef] [PubMed]

3. Alenezi, M.R.; Henley, S.J.; Emerson, N.G.; Silva, S.R.P. From 1D and 2D ZnO nanostructures to 3D hierarchical structures with enhanced gas sensing properties. Nanoscale 2014, 6, 235-247. [CrossRef] [PubMed]

4. Alenezi, M.R.; Alshammari, A.S.; Jarowski, P.D.; Alzanki, T.H.; Henley, S.J.; Silva, S.R.P. ZnO nanodisk based UV detectors with printed electrodes. Langmuir 2014, 30, 3913-3921. [CrossRef]

5. Alenezi, M.R.; Alzanki, T.H.; Almeshal, A.M. Nanowire Array Based UV Detectors. Int. J. Sci. Res. 2014, 3, 588-591.

6. Zhou, X.; Xie, Z.X.; Jiang, Z.Y.; Kuang, Q.; Zhang, S.H.; Xu, T.; Huang, R.B.; Zheng, L.S. Formation of ZnO hexagonal micropyramids: A successful control of the exposed polar surfaces with the assistance of an ionic liquid. Chem. Commun. 2005, 5572-5574. [CrossRef]

7. Alenezi, M.R.; Alshammari, A.S.; Jayawardena, K.D.G.I.; Beliatis, M.J.; Henley, S.J.; Silva, S.R.P. Role of the exposed polar facets in the performance of thermally and UV activated ZnO nanostructured gas sensors. J. Phys. Chem. C 2013, 117, 17850-17858. [CrossRef] [PubMed]

8. Shakthivel, D.; Dahiya, R.S.; Ahmad, M.; Alenezi, M.R.; Silva, S.R.P. 1D Semiconducting Nanostructures for Flexible and Large-Area Electronics; Cambridge University Press: Cambridge, UK, 2019.

9. Alenezi, M.R. UV Sensor Based on Single Metal Oxide Nanowire. Int. J. Eng. Sci. Res. Technol. 2014, 7, 755-758.

10. Henrich, V.E.; Cox, P.A. The Surface Science and Metal Oxides; Cambridge University Press: Cambridge, UK, 1994.

11. Schaub, R.; Wahlstrom, E.; Ronnaus, A.; Laegsgaard, E.; Stensgaard, I.; Besenbacher, F. Oxygen-Mediated Diffusion of Oxygen Vacancies on the $\mathrm{TiO}_{2}$ (110) Surface. Science 2003, 299, 377-379. [CrossRef] [PubMed]

12. An, W.; Wu, X.; Zeng, X.C. Adsorption of $\mathrm{O}_{2}, \mathrm{H}_{2}, \mathrm{CO}, \mathrm{NH}_{3}$, and $\mathrm{NO}_{2}$ on $\mathrm{ZnO}$ Nanotube: A Density Functional Theory Study. J. Phys. Chem. C 2008, 112, 5747-5755. [CrossRef]

13. Zhang, H.; Cen, Y.; Du, Y.; Ruan, S. Enhanced Acetone Sensing Characteristics of ZnO/Graphene Composites. Sensors 2016, 16, 1876. [CrossRef]

14. Alenezi, M.R. Hierarchical zinc oxide nanorings with superior sensing properties. Mater. Sci. Eng. B 2018, 236, 132-138. [CrossRef]

15. Al-Hadeethi, Y.; Umar, A.; Al-Heniti, S.; Kumar, R.; Kim, S.; Zhang, X.; Raffah, B. 2D Sn-doped ZnO ultrathin nanosheet networks for enhanced acetone gas sensing application. Ceram. Int. 2017, 43, 2418-2423. [CrossRef]

16. Fan, H.; Jia, X. Selective detection of acetone and gasoline by temperature modulation in zinc oxide nanosheets sensors. Solid State Ion. 2011, 192, 688-692. [CrossRef] 
17. Wen, W.; Wu, J.; Wang, Y. Large-size porous ZnO flakes with superior gas-sensing performance. Appl. Phys. Lett. $2012,100,262111$. [CrossRef]

18. Behera, B.; Chandra, S. An innovative gas sensor incorporating ZnO-CuO nanoflakes in planar MEMS technology. Sens. Actuators B Chem. 2016, 229, 414-424. [CrossRef]

19. Strom, J.G.; Jun, H.W. Kinetics of hydrolysis of methenamine. J. Pharm. Sci. 1980, 69, 1261-1263. [CrossRef]

20. Govender, K.; Boyle, D.S.; Kenway, P.B.; O’Brien, P. Understanding the factors that govern the deposition and morphology of thin films of $\mathrm{ZnO}$ from aqueous solution. J. Mater. Chem. 2004, 14, 2575-2591. [CrossRef]

21. Xu, C.K.; Shin, P.; Cao, L.L.; Gao, D. Preferential Growth of Long ZnO Nanowire Array and Its Application in Dye-Sensitized Solar Cells. J. Phys. Chem. C 2010, 114, 125-129. [CrossRef]

22. Wang, C.; Yin, L.; Zhang, L.; Xiang, D.; Gao, R. Metal oxide gas sensors: Sensitivity and influencing factors. Sensors 2010, 10, 2088-2106. [CrossRef] [PubMed]

23. Sun, Y.-F.; Liu, S.-B.; Meng, F.-L.; Liu, J.-Y.; Jin, Z.; Kong, L.-T.; Liu, J.-H. Metal Oxide Nanostructures and Their Gas Sensing Properties: A Review. Sensors 2012, 12, 2610-2631. [CrossRef] [PubMed]

24. Capone, S.; Forleo, A.; Francioso, L.; Rella, R.; Siciliano, P.; Spadavecchia, J.; Presicce, D.S.; Taurino, A.M. Solid state gas sensors state of the art and future activities. J. Optoelectron. Adv. Mater. 2003, 5, 1335-1348. [CrossRef]

25. Al-Hardan, N.; Abdullah, M.J.; Abdul Aziz, A. The gas response enhancement from $\mathrm{ZnO}$ film for $\mathrm{H}_{2}$ gas detection. Appl. Surf. Sci. 2009, 255, 7794-7797. [CrossRef]

26. Hongsith, N.; Wongrat, E.; Kerdcharoen, T.; Choopun, S. Sensor response formula for sensor based on ZnO nanostructures. Sens. Actuators B 2010, 144, 67-72. [CrossRef]

27. Alenezi, M.R.; Alzanki, T.H.; Almeshal, A.M.; Alshammari, A.S.; Beliatis, M.J.; Henley, S.J.; Silva, S.R.P. A model for the impact of the nanostructure size on its gas sensing properties. RSC Adv. 2015, 5, 103195. [CrossRef]

28. Tian, J.H.; Hu, J.; Li, S.S.; Zhang, F.; Liu, J.; Shi, J.; Li, X.; Tian, Z.Q.; Chen, Y. Improved seedless hydrothermal synthesis of dense and ultralong ZnO nanowires. Nanotechnology 2011, 22, 245601. [CrossRef]

29. Kim, W.; Choi, M.; Yong, K. Generation of oxygen vacancies in $\mathrm{ZnO}$ nanorods / films and their effects on gas sensing properties. Sens. Actuators B 2015, 209, 989-996. [CrossRef]

30. Jing, Z.H.; Zhan, J.H. Fabrication and Gas-Sensing Properties of Porous ZnO Nanoplates. Adv. Mater. 2008, 20 , 4547-4551. [CrossRef]

31. Murade, P.A.; Sangawar, V.S.; Chaudhari, G.N.; Kapse, V.D.; Bajpeyee, A.U. Gas sensing performance of nanocrystalline ZnO prepared by a simple route. Curr. Appl. Phys. 2010, 11, 451-456. [CrossRef]

32. Sysoev, V.V.; Button, B.K.; Wepsiec, K.; Dmitriev, S.; Kolmakov, A. Toward the Nanoscopic "Electronic Nose": Hydrogen vs Carbon Monoxide Discrimination with an Array of Individual Metal Oxide Nano- and Mesowire Sensors. Nano. Lett. 2006, 6, 1584-1588. [CrossRef]

33. Xiao, Y.; Lu, L.; Zhang, A.; Zhang, Y.; Sun, L.; Huo, L.; Li, F. Highly enhanced acetone sensing performances of porous and single crystalline $\mathrm{ZnO}$ nanosheets: High percentage of exposed (100) facets working together with surface modification with pd nanoparticles. ACS Appl. Mater. Interfaces 2012, 4, 3797-3804. [CrossRef] [PubMed]

34. Ge, M.; Xuan, T.; Yin, G.; Lu, J.; He, D. Controllable synthesis of hierarchical assembled porous ZnO microspheres for acetone gas sensor. Sens. Actuators B: Chem. 2015, 220, 356-361. [CrossRef]

35. Lin, Y.; Wei, W.; Wang, Y.; Zhou, J.; Sun, D.; Zhang, X.; Ruan, S. Highly stabilized and rapid sensing acetone sensor based on Au nanoparticle-decorated flower-like ZnO microstructures. J. Alloy. Compd. 2015, 650, 37-44. [CrossRef]

36. Chen, J.; Pan, X.; Boussaid, F.; Bermak, A.; Fan, Z. A hierarchical ZnO nanostructure gas sensor for human breath-level acetone detection. In Proceedings of the 2016 IEEE International Symposium on Circuits and Systems (ISCAS), Montreal, QC, Canada, 22-25 May 2016; pp. 1866-1869. 